\title{
Influence of Planning on Curriculum Implementation in Public Secondary Schools in Elgeyo-Marakwet County, Kenya \\ Peris Jeruto Cheserek $^{1^{*}}$, Dr. Justina Ndaita ${ }^{2}$ and Dr. Moses Kapkiai ${ }^{3}$
}

${ }^{1}$ Doctor of Philosophy Degree Educational Management (Planning Option)

${ }^{2,3}$ Lecturers Kisii University Kenya

DOI: $\underline{10.36347 / \text { sjahss.2021.v09i02.004 }}$

| Received: 03.02.2021 | Accepted: 17.02.2021 | Published: 26.02.2021

*Corresponding author: Peris Jeruto Cheserek

Abstract

The purpose of this study was to assess influence of planning on curriculum implementation in public secondary schools in Elgeyo-Marakwet County, Kenya. The study was guided by Lewin change theory. A pragmatic research paradigm was utilised in this study. The methodology used was mixed method research. This study utilised concurrent triangulation mixed research design. The target population for the research involved principals, deputy principals and heads of departments in 123 public secondary schools. A sample size of 37 secondary schools was selected to participate in the study. The respondents for the study were selected using stratified random sampling technique. The study utilised questionnaire as instruments for data collection. The research instruments were validated and tested for reliability prior to being administered to the field. Data collected was analysed using descriptive and inferential statistics. It is expected that the study findings will bring out specific and workable strategies that can be used by school managers in managing change. The study concludes that planning should include costing the process in terms of resources and time. The school should also take into consideration the staff's readiness and capacity to implement the change. The school should negotiate and ensure that energies are maximized since this will reduce conflict, and the direction of implementing education change is clear when planning is done and encourage more efficient working by setting deadlines by which certain education change tasks would have been completed. The study recommends that a good starting point on implementations of the curriculum is crucial. It was helpful if schools were already heading in the right direction, particularly if the implementation of the new curriculum could be linked to some form of existing practice or recent professional learning.

Key words: planning, curriculum, secondary schools, implementation, public.

Copyright (C) 2021 The Author(s): This is an open-access article distributed under the terms of the Creative Commons Attribution 4.0 International License (CC BY-NC 4.0) which permits unrestricted use, distribution, and reproduction in any medium for non-commercial use provided the original author and source are credited.

\section{INTRODUCTION}

Education is the greatest instrument for effecting national development. In Kenya, education is rapidly changing and is tailored towards meeting the social pillar objectives of Vision 2030 and Education for All goals. For this education to attain its objective, it requires many changes from policy and to the implementation stages. This is because Fullan, Cuttress and Kilcher [1] argue that change has been part of human behaviour throughout the known history of the world. The core of education and knowledge is change [2]. Fullan [3] defines educational change as learning how to do something new. Fullan [3] pointed out that the successful implementation of educational change is a complex process with no clear solution. This suggests why educational reforms are often not well implemented, causing a huge deficit of finance, human resources, and loss of potential.
Research shows that curriculum changes have regularly taken place in many parts of the world including, America, Canada, the United Kingdom, Australia, and New Zealand [4, 5]. Official reports show that educational standards in developing countries are declining, which suggests that schools are not actively responding to curriculum change [6]. Therefore, more needs to be done to ensure headteachers in public secondary schools are embracing change management strategies for effective curriculum implementation.

A number of scholars on curriculum change attest that members of the school staff require management support, effective leadership, open communication lines, and positive relations between themselves and heads if curriculum change is to be effective [7-9]. To ensure maximum participation in the planning and implementation of curriculum change by 
Peris Jeruto Cheserek et al., Sch J Arts Humanit Soc Sci, Feb, 2021; 9(2): 53-62

all staff, school administration leaders need to provide strong and effective leadership, open lines of communication and promote positive relations between teaching staff and themselves [10]. They also need to consult department staff and make them feel that their opinions are also valued [11]. This shows the importance of school heads towards promoting change management in schools for the attainment of educational goals.

School leaders need to create working environments that ensure that staff sees that managers are committed to the change process by sticking to the action plans. Failure to adhere to the agreed action plans by school leaders and Heads of Department (HODs) discourages staff from improving the quality of their work during curriculum change and breeds negative perceptions towards the change $[12,11]$. If school leaders show that they are committed to curriculum change and also regularly and effectively interact with and update subordinates about the progress of the change process, this has an effect of motivating subordinates in departments to show commitment [12]. For the education curriculum change initiative to succeed, it must be owned by the implementing staff. This is further confirmed in the literature that shows that change initiatives work best when introduced bottom-up and owned by the implementing team [13, 14].

\section{Statement of the Problem}

Education across the world is rapidly changing and technically tailored towards meeting certain goals such as the Sustainable Development Goals (SDGs) and the national goal of education. Organizations need avenues for change management in order to acquire new administrative schemes and plans. However, without acceptance of change management in organizations, there would be laxity in the implementation of important development agenda [15].

A research conducted in the United States by Van Bodegraven [16] noted that teacher implementation of school reforms varies widely and often results in inconsistent student outcomes. Teachers adopted or resisted change for complex reasons that are not fully understood. In Turkey, Canli et al. [5] argued that the determination of school administrators' tendencies towards change is considered as important. They found out that school administrators' tendencies towards change differed significantly in terms of variables of gender and educational level, while they did not differ significantly in terms of variables including the area of expertise, type of task, seniority, and type of school.

Coming to Africa, Kanelechi and Tope [4], a study in Nigeria established that most school administrators were not able to cope with the demands needed to implement education curriculum change. In South Africa, Themba [17], found out that some stakeholders were dissatisfied due to their poor involvement in managing change in their schools.

In Kenya, Bogonko [15], found out that many public secondary schools in Trans-Nzioa County faced financial and legal challenges in enabling change management practices. The observation from the international, regional, and local perspectives indicates that change management is an issue in secondary schools. The researcher also observed that inadequate studies had been done to determine how headteachers are coping with change management issues in their schools in Elgeyo-Marakwet County. Therefore, there is a need to investigate the influence of planning on curriculum implementation in public secondary schools in elgeyo-marakwet county, kenya.

\section{General Objective}

The purpose of the study was to investigate the influence of planning on curriculum implementation in public secondary schools in elgeyo-marakwet county, kenya.

\section{Research questions}

What is the influence of planning on curriculum implementation in public secondary schools in Elgeyo-Marakwet County, Kenya?

\section{Literature Review}

This chapter looks at the theoretical framework, the conceptual framework and empirical review

\section{Theoretical Framework}

This study was guided by; Lewin change theory

The study was guided by Lewin change theory. Lewin [18] introduced one of the earlier models of change theory, and his work is significant because he was one of the first researchers to conceptualize change as more of a process and not just an event. He understood that when contemplating a change, the existence of 'pros' and 'cons' will always be present. Lewin noted that the status quo would remain if the forces against change outweigh the forces for change. Change occurs when forces for change become greater than forces against. Lewin [18] proposed a three-step process in his change model.

1) Unfreezing current practice: This is getting ready for the change. Getting ready is a disruption of the normal routine. The more we feel that change is necessary, the more urgent it is, the more motivated we are to making the change and thus get ready to move away from our comfort zone. This is when the weighing 
up of the pros and cons must happen before further action is taken.

2) Change the practice: Lewin calls this process 'transition.' This is to do with the inner movement. People are 'unfrozen' already and are moving towards a new way of being. This step is a challenging one. A lot of support is needed in terms of training and coaching. A clear picture of the desired change must be communicated to the people who were affected, so they do not lose sight of where they are heading.

3) Refreezing new practice: This step is the establishment of stability. Change is finally accepted, and people become comfortable. However, this process can take time.

This final step in Kurt Lewin's three-step process has been criticized by other scholars for its rigidity [19]. This process does not fit very well with modern thinking, where flexibility rather than rigidity is demanded. This is due to a very high number of changes happening nowadays compared to the past. However, Kurt Lewin was more concerned about the reinforcement and sustainability of change, which is also a concern for many change leaders today.

\section{Empirical Review \\ Planning as a Strategy of Managing Educational Change}

The literature attests to the fact that curriculum change is the most effective if it is adequately and effectively planned $[11,20]$. Such planning includes costing the process in terms of resources and time. As part of the planning process, school leaders manage the implementation of the change process $[11,12,7]$ by being realistic about timelines and resources needed for the effective curriculum change, taking into consideration staff readiness and the capacity to implement the change. Identifying and nominating change leaders from within the department who can motivate others during the change; allowing for collaborative participation right from the planning stage to ensure buy-in and ownership of the change effort by the team members; defining what is negotiable not only to maximise energies but also to reduce conflict and ensuring the direction of implementing curriculum change is clear; encouraging more efficient working by setting deadlines by which certain curriculum change tasks would have been completed, and ensuring twoway communication right from the curriculum change planning to the implementation phases, and encouraging openness.

School strategic planning is key to the success of a school concerning the achievement of its mission, goals, and objectives [21]. In the United States of
America, Van Bodegraven [16] qualitative study explored how veteran teachers described their experiences with the school reforms and changes in classroom practices that occurred throughout their careers. Eight veteran K-12 public school teachers from a North Eastern state were interviewed using a semistructured, open-ended questionnaire. The findings indicated that the teachers who reported successful implementation of school reforms also reported that the internal factors of self-assessment, self-confidence, initiative, adaptability, and empathy, and the external factors of shared vision, team learning, and systems thinking were important to implementing change. When administrators supported teachers through quality professional development, adequate collaboration time, and respect for their professional judgment, participants embraced school reforms and changed their classroom practices.

Squires [22] explored how principals perceive their role in facilitating the implementation of the Common Core State Standards (CCSS). Through semistructured interviews with (current and past) elementary school principals leading nationally recognized, Blue Ribbon Schools of Excellence and document analysis of demographic data. This study makes sense of how instructional leaders negotiate and facilitate mandated change. Findings illuminated school culture and reflective practice of school leaders as important factors influencing implementation. Participants also identified three factors, from their perspectives, in successful change: the cultivation of a strong sustained school culture oriented toward continual improvement and student achievement, the strategic development within the school culture of authentic relationships and trustworthy leadership, and the establishment of shared decision-making and distribution of leadership within the school environment.

Kassim and Abdullah [8] investigated the learning environment in schools that influence teaching and learningin Malaysia. Schools with a positive learning environment can enhance academic excellence. The questionnaires were distributed to 161 secondary school teachers in Pahang, Malaysia. The data was analysed using SPSS version 11.0 in the form of mean, standard deviation, and correlation. The findings of the study indicated that principals promote a positive learning environment in schools, and the majority of them are positive about implementing changes in schools. These findings imply that principals possess a positive attitude towards change, thus will promote a positive learning environment in schools.

In UAE, Musabbeh [4] examined the requirement of change management necessary for secondary school principals in the emirate of $\mathrm{Abu}$ Dhabi in the light of new school model through 
conducting change management requirements, utilising a questionnaire on secondary school teachers in Abu Dhabi and Al Ain Educational Zones during 2011-2012. The study employs a qualitative research paradigm, where there are 47 items, and one open-ended question are combined in a questionnaire used to collect data. The study found out that the requirements of the change management necessary for school leaders were high in six clusters; building and communicating a school vision, planning for change, leading change, leading the process of teaching and learning, leading human and physical resources, and finally the community. The study also found out that the males were more positive towards change in education than the females. Also, years of experience impacted respondents' answers regarding change processes and requirements.

In South Africa, Nxumalo [19] research sought to investigate middle management roles in implementing the new curriculum at grade $10 \quad-12$ levels; it involved a small qualitative study of two schools in the KwaZulu-Natal midlands. It was found out that endeavours were made towards the planning process. There was a presence of the subject framework, work schedule, and the lesson plan. This indicated that the initial process of designing the learning programmes was being done. However, data revealed that middle managers fulfilled management rather than leadership function. Their roles consisted mostly of curriculum implementation processes at the expense of curriculum innovation and change. Barriers included a lack of time for proper planning and innovation due to a full teaching load as well as a lack of training by the Department of Education in the area of curriculum development and innovation.

Eimuhi [23] examined the importance of the school administrators (principal) in ensuring proper curriculum implementation (innovations) in Nigerian Secondary Schools. The sustainance of curriculum implementation includes programme implementation, change strategies, school supervision, staff role, educational change, organizational communication, etc. Curriculum implementations were faced with challenges of inefficient instructional supervision, teacher's commitment, pedagogy, inadequate materials, and facilities. It was concluded that the school administrators are also responsible for the success of the implementation process, that they should ensure that the newly developed curriculum and instructional materials are domesticated at the State and School levels.

Ndidi [9] study was aimed at determining the strategic planning competencies utilized by secondary school principals in Anambra State. The study was a descriptive survey involving all the 268 principals and 268 vice-principals in the public secondary schools in Anambra State. Findings indicated that principals utilized strategic planning competencies to a low extent going by the mean ratings of the principals and the viceprincipals. There were also no significant differences between the mean ratings of less and more experienced principals on their utilization of the strategic planning competencies. Poor utilization of strategic planning competencies by principals implies that it is either those principals were not adequately trained and prepared to strategically manage schools for effective results or that the training they received was no longer adequate to meet the challenges of emerging issues in secondary school management.

Olibie [6] study was to identify the curriculum planning practices and the challenges of secondary school principals in Anambra State in an era of knowledge and learning management. A descriptive survey design was used. The entire population of 268 principals was studied; hence, there was no sampling. The findings of the study indicated that there is insufficient curriculum planning among the principals. The perceived challenges faced by principals in school curriculum planning include inadequate allocation of resources and funds for school curricula and cocurricular activities, incompetence and poor understanding of curriculum change visions, inadequate training on curriculum innovations, and poor ability to use statistical data to make inferences for curriculum improvement.

Rudhumbu [14] examined the role of academic middle managers (AMMs) in the planning and implementation of curriculum change in private higher education institutions in Botswana. This study employed a mixed-methods research approach that utilised a structured questionnaire and a semi-structured interview guide to gather data on the AMMs role in the planning and implementation of curriculum change in PHEIs in Botswana. The study showed that the role of AMMs in the planning and implementation of curriculum change in PHEIs was too complex and demanding because they spent most of their time on daily administrative routines instead of on core academic activities such as planning and implementing curriculum change in their departments.

Okiiya, Kisiangani and Oparanya [24] study attempted to relate public secondary schools with the practice of generally established change management best practices. The specific objectives of the study were to establish change management practices adopted by Public Secondary Schools in Siaya Sub County. The school managers stated that they moderately practiced aspects of planning, committed leadership, workforce alignment, stakeholder involvement, and had defined governance structures in their institutions. However, the extents were varying from one school to the next. Multiple regressions were run using the change 
management practices dimensions established against performance dimensions of student enrolment, participation in co-curricular activities, KCSE achievement, financial management, and provision of teaching and learning resources, and development of school infrastructure. The study found out that change management practices adopted by the institutions significantly influenced performance.

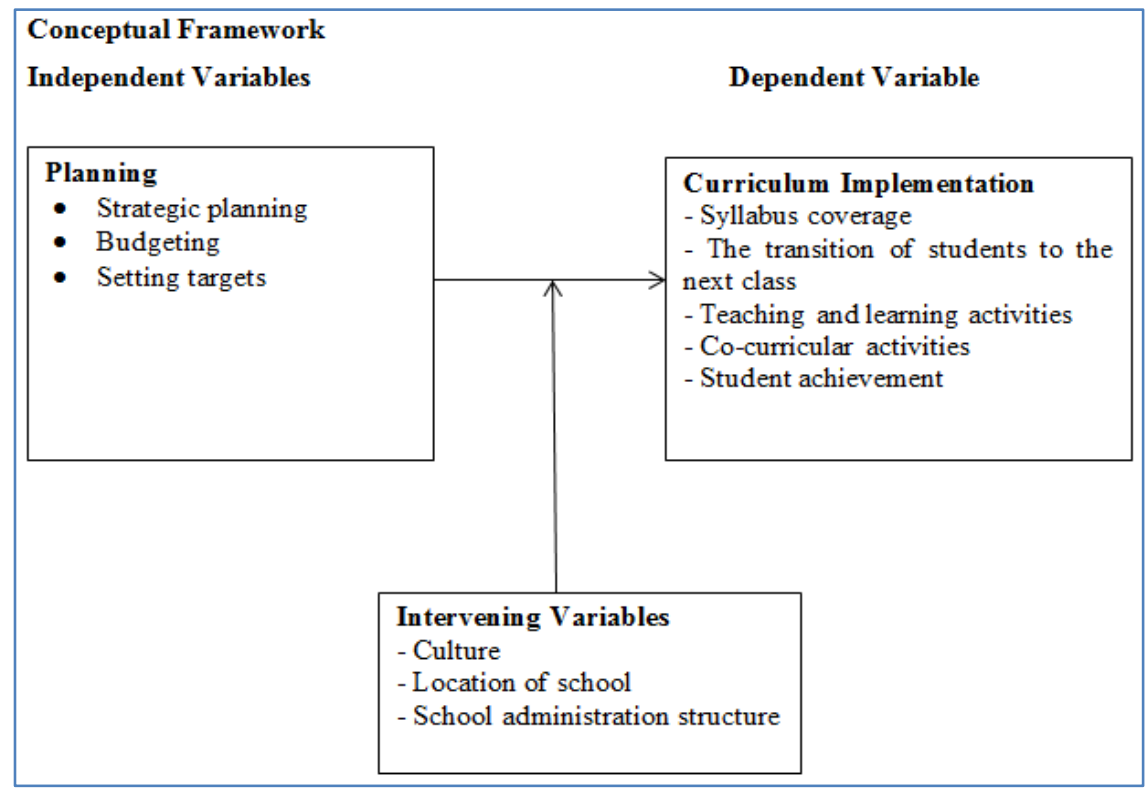

Fig-1: Conceptual Framework

\section{RESEARCH METHODOLOGY \\ Research Design}

This study utilised concurrent triangulation mixed research design. Concurrent triangulation design involves collecting quantitative and qualitative data concurrently $[2,25]$.

\section{Target Population}

The study target population comes from 123 public secondary schools in Elgeyo-Marakwet County. The respondents for the study involved a population of 1235 that was made up of; principals, deputy principals, and heads of departments in 123 public secondary schools. Table 1 shows the target population for the research.

Table-1: Target Population

\begin{tabular}{|l|l|l|l|l|l|}
\hline & $\begin{array}{l}\text { Keiyo } \\
\text { South }\end{array}$ & $\begin{array}{l}\text { Keiyo } \\
\text { North }\end{array}$ & Marakwet East & $\begin{array}{l}\text { Marakwet } \\
\text { West }\end{array}$ & Total \\
\hline Principals & 40 & 28 & 20 & 35 & 123 \\
\hline Deputy principals & 40 & 28 & 20 & 35 & 123 \\
\hline HODs & 320 & 224 & 160 & 280 & 984 \\
\hline Directors of Education & & & & & 5 \\
\hline Total & $\mathbf{4 0 0}$ & $\mathbf{2 8 0}$ & $\mathbf{2 0 0}$ & $\mathbf{3 5 0}$ & $\mathbf{1 2 3 5}$ \\
\hline
\end{tabular}

Source: County Director of Education Office (2017)

\section{Sampling Procedure and Sample Size}

According to Mugenda and Mugenda [26], a sample size of $30 \%$ would effectively represent the entire population even if the findings were generalized if the sample is evenly distributed and homologous. From this knowledge, this study's sample size was 37 schools that were selected through stratified random sampling. Table 2 shows the sample size for the study.

Table-2: Sample Size

\begin{tabular}{|l|l|l|l|l|l|l|l|l|l|}
\hline & \multicolumn{2}{|l|}{ Keiyo South } & \multicolumn{2}{l|}{ Keiyo North } & \multicolumn{2}{l|}{ Marakwet East } & \multicolumn{2}{l|}{ Marakwet West } & Total \\
\hline & $\mathbf{N}$ & $\mathbf{n}$ & $\mathbf{N}$ & $\mathbf{n}$ & $\mathbf{N}$ & $\mathbf{n}$ & $\mathbf{N}$ & $\mathbf{n}$ & \\
\hline Principals & 40 & 12 & 28 & 8 & 20 & 6 & 35 & 11 & 37 \\
\hline Deputy principals & 40 & 12 & 28 & 8 & 20 & 6 & 35 & 11 & 37 \\
\hline HODs & 320 & 96 & 224 & 67 & 160 & 48 & 280 & 84 & 295 \\
\hline Directors of Education & & & & & & & & & 5 \\
\hline Total & $\mathbf{4 0 0}$ & $\mathbf{1 2 0}$ & $\mathbf{2 8 0}$ & $\mathbf{8 4}$ & $\mathbf{2 0 0}$ & $\mathbf{6 0}$ & $\mathbf{3 5 0}$ & $\mathbf{1 0 5}$ & $\mathbf{3 7 4}$ \\
\hline
\end{tabular}

Source: County Director of Education Office (2017) 


\section{DATA ANALYSIS TECHNIQUES}

Descriptive statistics were used including, proportions, measures of central tendency, and frequency distributions to analyse data. The inferential method includes Karl Pearson Product Correlation. Qualitative data was condensed using categorization of data according to related responses from various respondents. The related responses were then counted and quantified. Unquantifiable qualitative data were grouped thematically and a general narrative written to describe the results. Analysed data was presented using tables, graphical illustrations, and narrations.

\section{RESEARCH FINDINGS AND DISCUSSIONS Response Return Rate}

The study targeted 123 public secondary schools in Elgeyo-Marakwet County. As such, 374 questionnaires were issued to the respondents. 306 questionnaires were duly filled and returned. This translates to $81.8 \%$, as shown in Table 3. This response rate is considered very good to enable the determination of the phenomenon that exists as it is in line with Mugenda and Mugenda [26] assertion. They state that a response rate of above $75 \%$ is recommended for the generalization of the study findings. This is also in line with Cooper and Schindler [27], arguing that the research whose response rate is above $75 \%$ is adequate for a study that is social science in nature.

Table-3: Response rate

\begin{tabular}{|l|l|l|}
\hline Response rate & Frequency & Percentage \\
\hline Responded & 306 & 81.8 \\
\hline Not responded & 68 & 18.2 \\
\hline Total & $\mathbf{3 7 4}$ & $\mathbf{1 0 0}$ \\
\hline
\end{tabular}

\section{Planning}

The study first sought to find out the influence of planning on curriculum implementation in public secondary schools in Elgeyo-Marakwet County, Kenya. Table 4 presents the study results.

The study findings on the influence of planning on curriculum implementation in public secondary schools in Elgeyo-Marakwet County, Kenya shows that $74(24.2 \%)$ of the respondents strongly agree, $166(54.2 \%)$ of the respondents agree, $39(12.7 \%)$ of the respondents are undecided, and $27(8.8 \%)$ of the respondents disagree with the statement that planning includes costing the process in terms of resource and time (Mean=3.94, Standard deviation=0.8489). The study results coincide with Van Bodegraven [16], who did a qualitative study in exploring how veteran teachers described their experiences with school reform and changes in classroom practices that occurred over the course of their careers. Findings indicated that the teachers who reported successful implementation of school reforms also reported that the internal factors of self-assessment, self-confidence, initiative, adaptability, and empathy, and the external factors of shared vision, team learning, and systems thinking were important to implementing a change.

Also, 23(7.5\%) of the respondents strongly agree, $45(14.7 \%)$ agree, 26(8.5\%) undecided and $212(69.3 \%)$ disagree with the statement that the school is realistic about timelines and resources needed for effective curriculum change (Mean=2.70, Standard deviation=0.8113). The study concurs with Musabbeh [4], who examined the requirement of change management necessary for secondary school principals in the emirate of Abu Dhabi in light of the new school model through conducting change management requirements. The study found out that the requirements of change management necessary for school leaders were high in six clusters, building and communicating a school vision, planning for change, leading change, leading the process of teaching and learning, leading human and physical resources, and finally, the community.

Furthermore, 55(17.9\%) of the respondents strongly agree, $163(53.3 \%)$ agree, 42(13.7\%) undecided, 46(15.0\%) disagree and (\%) strongly disagree with the statement that they take into consideration staffs readiness and capacity to implement the change (Mean=3.74, Standard deviation $=0.9244$ ) the study concurs with Rudhumbu [14] who examined the role of academic middle managers (AMMs) in the planning and implementation of curriculum change in private higher education institutions in Botswana. The study showed that the role of AMMs in the planning and implementation of curriculum change in PHEIs was too complex and demanding because they spent most of their time on daily administrative routines instead of on core academic activities such as planning and implementing curriculum change in their departments.

Further, $27(8.8 \%)$ of the respondents strongly agree, $187(61.1 \%)$ agree, $45(14.7 \%)$ undecided and $47(15.4 \%)$ disagree with the statement that they identify and nominate change leaders from within the school who can motivate others during the change (Mean=3.63, Standard deviation=0.8474) the study agrees with Kassim and Abdullah [8] who investigated the learning environment in schools that influence teaching and learning in Malaysia. Schools with a positive learning environment can enhance academic excellence. The findings of the study indicate that principals promote a positive learning environment in schools, and the majority of them are positive about implementing changes in schools. These findings imply that principals possess a positive attitude towards change, thus will promote a positive learning environment in schools. 
Another, 53(17.3\%) of the respondents strongly agree, $18(5.6 \%)$ agree, $80(26.1 \%)$ undecided, $134(43.8 \%)$ disagree and 21(6.9\%) strongly disagree with the statement that there is collaborative participation right from the planning stage to ensure buy-in and ownership of the change effort by team members in the school (Mean=2.59, Standard deviation=1.0590) the study findings agree with Okiiya, Kisiangani and Oparanya [24] who studied on how to relate public secondary schools with the practice of generally established change management best practices. The study found out that change management practices adopted by the institutions significantly influenced performance.

Also, $80(26.1 \%)$ of the respondents strongly agree, $167(54.6 \%)$ agree, 31(10.1\%) undecided, $25(8.2 \%)$ disagree and $3(0.9 \%)$ strongly disagree with the statement that they do negotiate and ensures that energies are maximized (Mean=3.97, Standard deviation $=0.8828$ ) The study also agrees with Squires [22] who explored how principals perceive their role in facilitating implementation of the Common Core State Standards (CCSS). Findings illuminated school culture and reflective practice of school leaders as important factors influencing implementation. Participants also identified three factors, from their perspectives, in successful change: the cultivation of strong sustained school culture oriented toward continual improvement and student achievement, the strategic development within the school culture of authentic relationships and trustworthy leadership, and the establishment of shared decision-making and distribution of leadership within the school environment.

Further, $79(25.8 \%)$ of the respondents strongly agree, $158(51.6 \%)$ agree, $26(8.5 \%)$ undecided, and 43(14.1\%) disagree with the statement that conflict is reduced. The direction of implementing educational change is clear when planning is done (Mean=3.89, Standard deviation=0.9469). The study also agrees with Squires [22], who explored how principals perceive their role in facilitating the implementation of the Common Core State Standards (CCSS). Findings illuminated school culture and reflective practice of school leaders as important factors influencing implementation. Participants also identified three factors, from their perspectives, in successful change: the cultivation of strong sustained school culture oriented toward continual improvement and student achievement, the strategic development within the school culture of authentic relationships and trustworthy leadership, and the establishment of shared decision-making and distribution of leadership within the school environment.
Also, 62(20.3\%) of the respondents strongly agree, 207(67.6\%) agree, 10(3.3\%) undecided, $26(8.5 \%)$ disagree and $1(0.3 \%)$ strongly disagree with the statement that they encourage more efficient working by setting deadlines by which certain education change tasks would have been completed (Mean=3.99, Standard deviation=0.7787) The study concurs with Nzoika and Aluko who sought to analyse the strategies school managers apply to improve academic performance of students in schools under free day secondary school education in Embu District, Embu County, Kenya. Despite these efforts, the expected improved students' academic performance was not realized due largely to the fact that most school managers had not undergone management skill training.

Finally, $50(16.3 \%)$ of the respondents strongly agree, 58(18.9\%) agree, 29(9.5\%) undecided, $168(54.9 \%)$ disagree and 1(0.3\%) strongly disagree with the statement that they ensure two-way communication right from education change planning to the implementation phases to promote openness (Mean=2.68, Standard deviation=0.9728). The study findings agree with Musabbeh [4] who examined the requirement of change management necessary for secondary school principals in the emirate of Abu Dhabi in light of new school model through conducting change management requirements utilising a questionnaire on secondary school teachers in Abu Dhabi and Al Ain Educational Zones during 2011-2012. The study found out that the requirements of change management necessary for school leaders were high in six clusters, building and communicating a school vision, planning for change, leading change, leading the process of teaching and learning, leading human and physical resources, and finally, the community. The study also found that males were more positive towards change in education than females. Also, years of experience impacted respondents' answers regarding change processes and requirements.

The study also reveals that planning has a positive influence on curriculum implementation in public secondary schools in Elgeyo-Marakwet County, Kenya. This implies that planning should include costing the process in terms of resources and time. The school should also take into consideration the staff's readiness and capacity to implement the change.

The school should negotiate and ensure that energies are maximized since this will reduce conflict, and the direction of implementing educational change is clear when planning is done and encourage more efficient working by setting deadlines by which certain education change tasks would have been completed. 
Table-4: Planning

\begin{tabular}{|c|c|c|c|c|c|c|c|c|}
\hline ttatements & No. & SA & $\mathbf{A}$ & UD & D & SD & Mean & $\begin{array}{l}\text { Std. } \\
\text { dev }\end{array}$ \\
\hline \multirow{2}{*}{$\begin{array}{l}\text { Planning includes costing the process in terms of } \\
\text { resource and time }\end{array}$} & Fig & 74 & 166 & 39 & 27 & 1.1 .0 & 3.94 & 0.8489 \\
\hline & $\%$ & 24.2 & 54.2 & 12.7 & 8.8 & 1.2 .0 & & \\
\hline \multirow{2}{*}{$\begin{array}{l}\text { The school is realistic about timelines and resources } \\
\text { needed for effective curriculum change }\end{array}$} & Fig & 23 & 45 & 26 & 212 & 1.3 .0 & 2.70 & 0.8113 \\
\hline & $\%$ & 7.5 & 14.7 & 8.5 & 69.3 & 1.4 .0 & & \\
\hline \multirow{2}{*}{$\begin{array}{l}\text { We take into consideration staff's readiness and } \\
\text { capacity to implement the change }\end{array}$} & Fig & 55 & 163 & 42 & 46 & 1.5 .0 & 3.74 & 0.9244 \\
\hline & $\%$ & 17.9 & 53.3 & 13.7 & 15.0 & 1.6 .0 & & \\
\hline \multirow{2}{*}{$\begin{array}{l}\text { We identify and nominate change leaders from within } \\
\text { the school who can motivate others during the change }\end{array}$} & Fig & 27 & 187 & 45 & 47 & 1.7 .0 & 3.63 & 0.8474 \\
\hline & $\%$ & 8.8 & 61.1 & 14.7 & 15.4 & 1.8 .0 & & \\
\hline \multirow{2}{*}{$\begin{array}{l}\text { There is collaborative participation right from the } \\
\text { planning stage to ensure buy-in and ownership of the } \\
\text { change effort by team members in the school }\end{array}$} & Fig & 53 & 18 & 80 & 134 & 21 & 2.59 & 1.0590 \\
\hline & $\%$ & 17.3 & 5.9 & 26.1 & 43.8 & 6.9 & & \\
\hline \multirow{2}{*}{$\begin{array}{l}\text { We do negotiate and ensures that energies are } \\
\text { maximized }\end{array}$} & Fig & 80 & 167 & 31 & 25 & 3 & 3.97 & 0.8828 \\
\hline & $\%$ & 26.1 & 54.6 & 10.1 & 8.2 & 0.9 & & \\
\hline \multirow{2}{*}{$\begin{array}{l}\text { Conflict is reduced, and the direction of implementing } \\
\text { education change is clear when planning is done }\end{array}$} & Fig & 79 & 158 & 26 & 43 & 0 & 3.89 & 0.9469 \\
\hline & $\%$ & 25.8 & 51.6 & 8.5 & 14.1 & 0 & & \\
\hline \multirow{2}{*}{$\begin{array}{l}\text { We encourage more efficient working by setting } \\
\text { deadlines by which certain education change tasks } \\
\text { would have been completed }\end{array}$} & Fig & 62 & 207 & 10 & 26 & 1 & 3.99 & 0.7787 \\
\hline & $\%$ & 20.3 & 67.6 & 3.3 & 8.5 & 0.3 & & \\
\hline \multirow{2}{*}{$\begin{array}{l}\text { We ensure two - way communication right from } \\
\text { education change planning to the implementation } \\
\text { phases to promote openness }\end{array}$} & Fig & 50 & 58 & 29 & 168 & 1 & 2.68 & 0.9728 \\
\hline & $\%$ & 16.3 & 18.9 & 9.5 & 54.9 & 0.3 & & \\
\hline 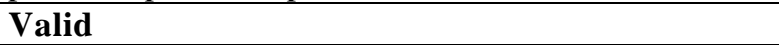 & & & & & & & & \\
\hline
\end{tabular}

\section{Overall Correlation Analysis}

The results of the correlation analysis are presented in Table 6 below.
Correlation results showed that relationship between planning and curriculum implementation was positive and statistically significant $(r=0.023, \mathrm{p}<0.05)$.

Table-6: Correlation Coefficient Matrix

\begin{tabular}{|l|l|l|l|}
\hline \multicolumn{2}{|c|}{ Curriculum implementation } & Planning \\
\hline Curriculum implementation & Pearson Correlation & 1 & \\
\cline { 2 - 4 } & Sig. (2-tailed) & & \\
\hline Planning & Pearson Correlation & $.023^{*}$ & 1 \\
\hline & Sig. (2-tailed) & 0.000 & \\
\hline
\end{tabular}

\section{SUMMARY, CONCLUSIONS AND RECOMMENDATION \\ Summary of the Study}

\section{Planning}

The first objective of the study was to find out the influence of planning on curriculum implementation in public secondary schools in Elgeyo-Marakwet County, Kenya. The study found out that the respondents agreed on all aspects of planning. They agreed that; planning includes costing the process in terms of resource and time, the school is realistic about timelines and resources needed for effective curriculum change, the school is realistic about timelines and resources required for effective curriculum change, they take into consideration staffs readiness and capacity to implement the change, they identify and nominate change leaders from within the school who can motivate others during the change, there is collaborative participation right from the planning stage to ensure buy-in and ownership of the change effort by team members in the school, they do negotiate and ensures that energies are maximized, conflict is reduced and the direction of implementing education change is clear when planning is done, they encourage more efficient working by setting deadlines by which certain education change tasks would have been completed and that they ensure a two-way communication right from education change planning to the implementation phases to promote openness.

The study findings also showed that planning had a strong positive correlation on curriculum implementation. The study also reveals that planning has a positive influence on curriculum implementation in public secondary schools in Elgeyo-Marakwet County, Kenya. This implies that planning should include costing the process in terms of resources and time. The school should also take into consideration the staff's readiness and capacity to implement the change. 
The school should negotiate and ensure that energies are maximized since this will reduce conflict, and the direction of implementing education change is clear when planning is done and encourage more efficient working by setting deadlines by which certain education change tasks would have been completed.

\section{CONCLUSION OF THE STUDY}

The study concluded that planning should include costing the process in terms of resources and time. The school should also take into consideration the staff's readiness and capacity to implement the change. The school should negotiate and ensure that energies are maximized since this will reduce conflict, and the direction of implementing education change is clear when planning is done and encourage more efficient working by setting deadlines by which certain education change tasks would have been completed.

\section{RECOMMENDATIONS OF THE STUDY}

The study recommends a good starting point on implementations of the curriculum is crucial. It was helpful if schools were already heading in the right direction, particularly if the implementation of the new curriculum could be linked to some form of existing practice or recent professional learning.

\section{REFERENCE}

1. Kilcher B, Da Rold M, Boscherini-da Silva V, inventors; Kerr Hawe SA, assignee. Device and system for separation and matrix retention and adaptation during dental restoration and method for preparing tooth using system. United States patent application US 10/904,812. 2005 Jun 2.

2. Owolabi SA, Makinde OG. The effects of strategic planning on corporate performance in university education: A study of Babcock University. Kuwait Chapter of the Arabian Journal of Business and Management Review. 2012 Dec 1;2(4):27.

3. Fullan M. The new meaning of educational change. Routledge; 2007.

4. Musabbeh Al Ka'abi FS. Requirements of Change Management Necessary for Secondary School Leaders in the Emirate of Abu Dhabi in Light of New School Model.

5. Canlı S, Demirtaş H, Niyazi ÖZ. Okul yöneticilerinin değişime yönelik eğilimleri. Elementary Education Online. 2015 Apr 19;14(2).

6. Olibie EI. Curriculum Planning in Secondary Schools: Principals' practice and challenges in an Era of knowledge and learning management. International Journal of academic research in progressive education and development. Vol. 2013;2.

7. Jones CA, Duckett I. Planning and managing curriculum change. Learning Skills Network. Retrieved from www. LSNeducation. org. uk.[Accessed: 9th April 2014]. 2006.
8. Jainabee MK, Jamelaa BA. Promoting Learning Environment and Attitude towards Change among Secondary School Principals in Pahang Malaysia: Teachers' Perceptions. Procedia-Social and Behavioral Sciences. 2011;28:45-9.

9. Ndidi PE. Strategic Planning Competencies Utilized By Principals In Managing Emerging Issues In Secondary Education In Anambra State of Nigeria. Nnamdi Azikiwe University Awka. 2017.

10. Benwari NN, Dambo BI. Improving secondary schools management through transformational leadership approach and management information systems. Journal of Educational and Social Research. 2014 Sep 4;4(6):401-.

11. Curee. Effective Curriculum Innovation: How can school leaders manage curriculum change effectively? Coventry: Center for the use of research and evidence in education. 2010.

12. Mace J. Managing Curriculum change. Learning skills Development Agency. 2001. Retrieved from www.LSagency.org.uk. [Accessed: 4th May 2017].

13. Salkić I. Impact of strategic planning on management of public organizations in Bosnia and Herzegovina. Interdisciplinary Description of Complex Systems: INDECS. 2014 Jan 31;12(1):61-77.

14. Rudhumbu N. The role of academic middle managers in the planning and implementation of curriculum change in private higher education institutions in Botswana (Doctoral dissertation, University of Fort Hare).

15. Bogonko OO. Effects of ownership structure on firm's dividend policy: evidence from Nairobi Securities Exchange (Doctoral dissertation, University of Nairobi).

16. Van Bodegraven D. Implementing Change: How, Why, and When Teachers Change Their Classroom Practices. D.Phil Dissertation, Walden University. 2015.

17. Poister TH. The future of strategic planning in the public sector: Linking strategic management and performance. Public Administration Review. 2010 Dec;70:s246-54.

18. Lewin K. Field theory in social science: selected theoretical papers (Edited by Dorwin Cartwright.).1951.

19. Nxumalo VN. Investigating Middle Management Roles in Implementing the New Curriculum at Grade 10 - 12 Level: A Case of Two Schools in the Kwazulu-Natal Midlands. MED Dissertation, University of KwaZulu-Natal.2009.

20. O'Shannassy T. Investigating the role of middle managers in strategy-making process: An Australian mixed method study. Journal of Management \& Organization. 2014 Mar 1;20(2):187-205.

21. Mwangi DK. Challenges Facing Public Secondary School Managers In The Implementation Of 
Strategic Plans In Gatundu North District, Kiambu County. MED Project, Kenyatta University, Kenya.2015.

22. Squires TM. "Leading Curricular Change: The Role Of The School Principal In Implementation Of The Common Core State Standards". Dissertations - ALL. Paper 406. Syracuse University.2015.

23. Eimuhi JO. The Role of School Managers in Curriculum Implementation in Nigerian Secondary Schools. 2017; Retrieved online from http://foeaau.com/? On 23 March 2017.
24. Okiiya AS. Change management and performance of public secondary schools in Siaya Sub-county, Kenya (Doctoral dissertation, University of Nairobi).

25. Teddlie C, Tashakkori A. Foundations of mixed methods research: Integrating quantitative and qualitative approaches in the social and behavioral sciences. Sage; 2009.

26. Mugenda AG. Social science research: Theory and principles. Nairobi: Applied. 2008.

27. Cooper DR, Schindler PS, Sun J. Business research methods. New York: Mcgraw-hill; 2006. 